\title{
Optimum Sizing Modelling of Sinusoidal Pulse Width Modulation (SPWM) Transformerless Photovoltaic Inverter (TPVI) System Based on Solar Radiation in Kangar Malaysia
}

\author{
H. Alam, M. Y. Mashor, M. Irwanto, A.H. Haziah, M. Masri
}

\begin{abstract}
This paper presents the daily, monthly and annual solar irradiation in Kangar. They are observed and analyzed to obtain the potential of Sinusoidal Pulse Width Modulation Transformerless Photovoltaic Inverter (SPWM TPVI) system application. It is due to the SPWM TPVI system is operated directly by PV module, therefore an optimization sizing of the system is studied in this paper. The optimum sizing is based on the solar irradiance, temperature, PV power and demanded power of SPWM TPVI. They are created in mathematical modeling. The results show that the average monthly solar radiation for the year of 2015 is $407.0 \mathrm{~W} / \mathrm{m}^{2}$ or $4861.44 \mathrm{Wh} / \mathrm{m}^{2}$. It is classified in very high solar radiation and indicates that the sky in Kangar is very clear and very suitable for generating the SPWM TPVI system. The optimum PV module string number is 21 (difference between the generated power and demanded power is zero). It is due to there is three PV modules in one string that connected in series, therefore the total number of PV module is 63 to generate the $1200 \mathrm{~W}$ SPWM TPVI system.
\end{abstract}

Keywords - Optimum sizing, SPWM, photovoltaic, inverter.

\section{INTRODUCTION}

PV performance depends on the solar irradiation and temperature. If the solar irradiation increases and the temperature is constant, thus the PV performance will increase. Inversely, if the temperature increases and the solar irradiation is constant, thus the PV performance will decrease [1]-[4]. The PV performance affects the capability of the charging system in the PV inverter application. A high PV performance will produce a high current [5].

Normally, the low frequency $(50 \mathrm{~Hz})$ inverter uses a transformer that it is big, heavy and expensive and the simplest technique to invert DC power into AC power is to generate a square wave. However, the harmonic content of the square wave is relatively high, also the efficiency of this waveform is relatively low. For reducing the manufacturing cost, size, and weight, a sinusoidal pulse wave modulation (SPWM)

H. Alam, M. Irwanto, M. Masri, Department of Electrical Engineering, Institut Teknologi Medan (ITM), Medan, Indonesia, Email: hermans@yahoo.com

M. Y. Mashor, School of Mechatronic Engineering, Universiti Malaysia Perlis (UniMAP), Perlis, Malaysia

H. Alam, M. Irwanto, A. H. Haziah, School of Electrical System Engineering, Universiti Malaysia Perlis (UniMAP),Perlis, Malaysia, Email: irwanto@unimap.edu.my,mirwanto@yahoo.com transformerless PV inverter (TPVI) is suitable to be constructed and developed [6]-[9].

This paper presents the daily, monthly and annual solar irradiation in Kangar. They are observed and analyzed to obtain the potential of SPWM TPVI system application. It is due to the SPWM TPVI system is operated directly by PV module, therefore an optimization sizing of the system is important to be studied.

\section{II.RESEARCH METHODOLOGY}

\section{A. Installation of Weather Station, PV Array and SPWM TPVI System}

The SPWM TPVI system is installed in front of Centre of Excellence for Renewable Energy, Universiti Malaysia Perlis, in Kangar, Malaysia as shown in Fig. 1. Its main energy source is a PV array which consists of three unit of $91.8 \mathrm{~V}, 60 \mathrm{~W}$ PV modules as shown in Fig. 2. The PV array converts solar energy (solar irradiance) to be DC electricity. In this research, the solar irradiance and temperature are recorded by a weather station every minute as shown in Fig. 2. The solar irradiance and temperature affects the PV array voltage.

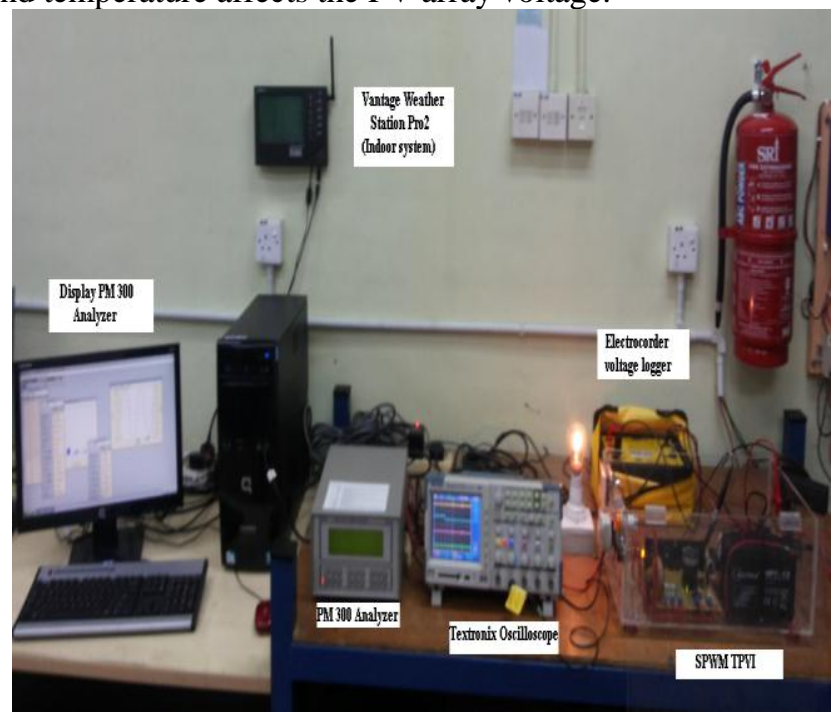

Fig. 1 SPWM TPVI system 


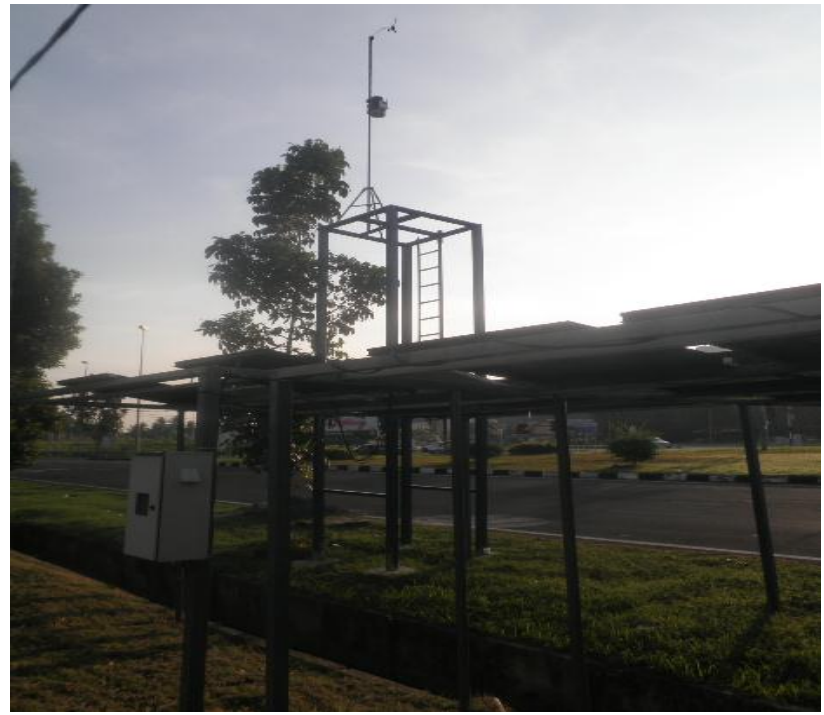

Fig. 2 Weather station and PV array

\section{B. Optimum Sizing of SPWM TPVI System}

The proposed optimum sizing of SPWM TPVI system based on mathematical modeling of the PV panel, energy generated by PV module and SPWM TPVI system as explained below.

1. Data of solar irradiance and temperature.

Daily data of solar irradiance and temperature through the year of 2015 are needed to calculate maximum power of PV module. This data are recorded by Centre of Excellent for Renewable Energy (CERE) Station, Universiti Malaysia Perlis, in Kangar, Perlis, Northern Malaysia.

2. SPWM TPVI demanded load

The daily inverter demanded power load through a year is observed and calculated, the total energy as given below [10].

$$
W_{d e m}=\sum_{n=1}^{365}\left[(\Delta T)\left(P(n)_{d e m}\right)\right]
$$

Where $W_{d e m}$ is SPWM TPVI demanded energy, $\Delta T$ is the time between the samples (in this case one day), $P_{d e m}$ is SPWM TPVI demanded power, $n$ is the sampling time (day in year).

3. Type selection of PV module.

Data sheet of $60 \mathrm{~W}, 91.8 \mathrm{~V}$, Kaneka G-SA060 amorphous silicon (a-Si) PV module is used in this study. The data sheet of the PV module is needed to calculate its maximum power that related to the solar irradiance, temperature. The connection of PV array that connected to the SPWM TPVI system is shown in Fig. 3.

4. Mathematical modeling of PV module

The daily maximum power of PV module relates to the solar irradiance and temperature falling on the PV module. To calculate the daily maximum power of the PV module, firstly current and voltage of the PV module calculated following (2). Secondly, I-V curve of the PV module is plotted and found its maximum power.

The mathematical modeling of open circuit voltage and circuit current of a performance of PV module follows what was suggested by [11]. The application of this model requires the data of minimum open voltage, $V_{\min }$ and maximum open voltage, $V_{\max }$ in two operation points with low solar irradiation phase, $\alpha_{\min }$ of $200 \mathrm{~W} / \mathrm{m}^{2}$ and high solar irradiation phase, $\alpha_{\max }$ of $1000 \mathrm{~W} / \mathrm{m}^{2}$ at the same nominal temperature, $T_{N}$ of $25^{0} \mathrm{C}$.

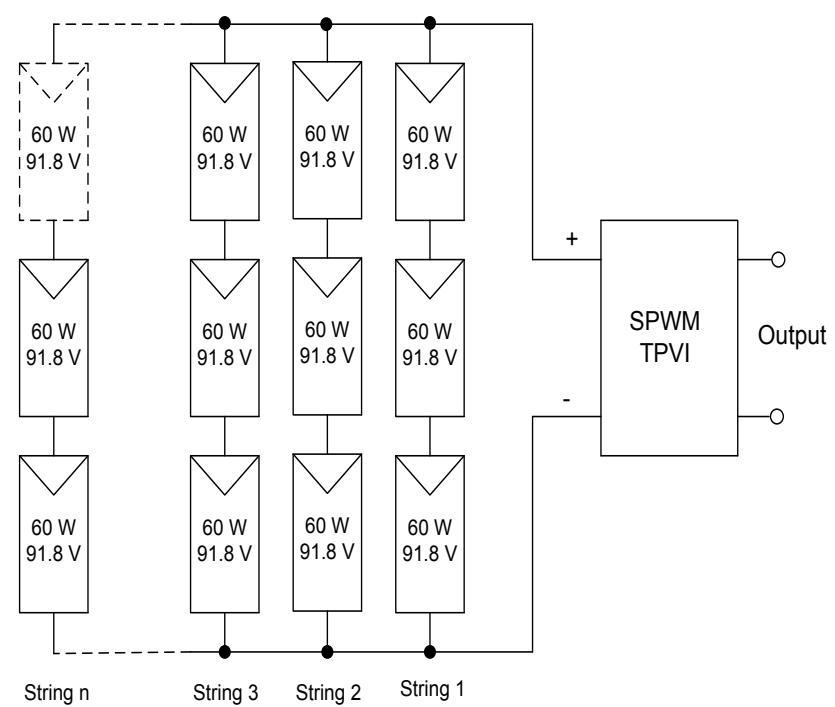

Fig. 3 The connection of PV array that connected to the SPWM TPVI

Beside those four parameters, five parameters from the data sheet of PV module are required to simulate the performance of PV module. They are the short circuit current $I_{s c}$, open circuit voltage at maximum peak point, $V_{M P P}$ and current at the maximum peak point, $I_{M P P}$, all at the STC (standard test condition) as well as the coefficient of temperature for the short circuit current, $T C_{i}$ and the coefficient of temperature for open circuit voltage, $T C_{v}$. The parameter of " $b$ " is the PV model fixed parameter. It influences the I-V curve in the maximum power point. The circuit current $I(\alpha, T, V)$ and open circuit voltage $V_{o c}(\alpha, T)$ as function of solar irradiation, temperature and voltage are given by [11] are shown in (2) to (5).

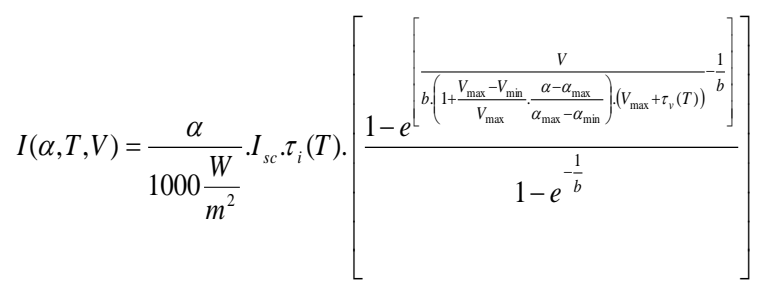

When $I(\alpha, T, V)=0 \mathrm{~A}$, the open circuit voltage is given by

$$
V_{o c}(\alpha, T)=\left[1+\frac{V_{\text {max }}-V_{\text {min }}}{V_{\text {max }}} \cdot \frac{\alpha-\alpha_{\text {max }}}{\alpha_{\text {max }}-\alpha_{\text {min }}}\right] \cdot\left[V_{\text {max }}+\tau_{v}(T)\right]
$$




$$
\begin{aligned}
& \tau_{i}(T)=1+\frac{T C_{i}}{100 \%} .\left(T-T_{N}\right) \\
& \tau_{v}(T)=T C_{v} .\left(T-T_{N}\right)
\end{aligned}
$$

5. Mathematical modeling of PV - wind power hybrid system

The daily maximum power of the PV module and wind power generation are used to calculate the total annual energy generated by the PV - wind power hybrid system that calculated using this equation [10].

$W_{g e n}=\sum_{n=1}^{365}\left[(\Delta T)\left(K_{p v} P(n)_{p v}\right)\right]$

where $W_{g e n}$ is total annual energy is generated by the PV module and $K_{p v}$ represents the string number of PV module used and $P_{p v}$ is the power generated by a specified PV module.

6. Number of PV module

The number of PV module is found using this formulation.

$$
\Delta W=W_{g e n}-W_{d e m}
$$

where $\Delta W$ is difference between the generated energy and demanded energy. Number of PV module is optimum if the system is balance. In order for the SPWM TPVI system and load to balance over a given period of time, the curve of $\Delta W$ versus time must have an average of zero over the same time period. A positive value of $\Delta W$ indicates the availability of generation and negative $\Delta W$ indicates generation deficiency.

\section{RESULTS AND DISCUSSION}

\section{A. Solar Radiation Potential For Generation of SPWM TPVI System}

The daily solar radiation in Kangar is analyzed according to the measured data at Centre of Excellent for Renewable Energy (CERE) Station, Kangar for the year of 2015. The analysis is very important to decide that Kangar is suitable or not to generate the SPWM TPVI. The analysis is based on the level of solar radiation, it is suitable if the solar radiation is above $3000 \mathrm{Wh} / \mathrm{m}^{2}$ or above $250 \mathrm{~W} / \mathrm{m}^{2}$ [12].

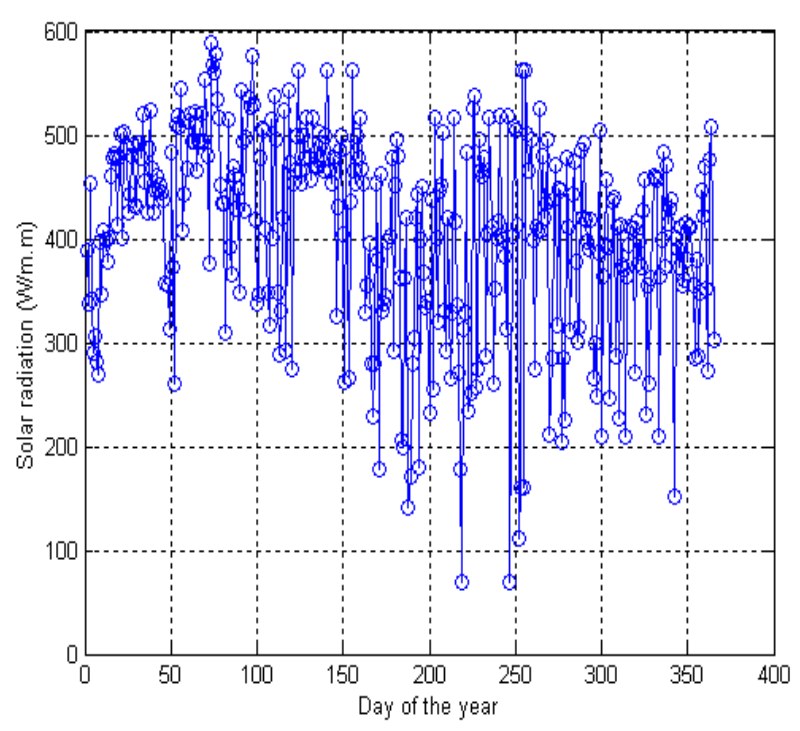

Fig. 4 Daily solar radiation throughout year 2015

Fig. 4 shows the daily solar radiation throughout year 2015 . The lowest solar radiation of $68.73 \mathrm{~W} / \mathrm{m}^{2}$ occur on $8^{\text {th }}$ August 2015 and $4^{\text {th }}$ September 2016. They indicated that the sky was cloud and the days could not generate the SPWM TPVI system. The highest solar radiations of $589.3 \mathrm{~W} / \mathrm{m}^{2}$ occur on $14^{\text {th }}$ March 2015. It indicated that the sky was very clear and the day was very good to generate the SPWM TPVI system. The average solar radiation through the year of 2015 is 478.07 $\mathrm{W} / \mathrm{m}^{2}$. It is higher than $250 \mathrm{~W} / \mathrm{m}^{2}$ and indicates that in Kangar is suitable to generate the SPWM TPVI system.

Fig. 5 and 6 show minimum, maximum and average monthly solar radiation for the year of 2015 in $\mathrm{W} / \mathrm{m}^{2}$ and $\mathrm{Wh} / \mathrm{m}^{2}$, respectively. Their lowest minimum, highest maximum solar radiation are shown in Table I

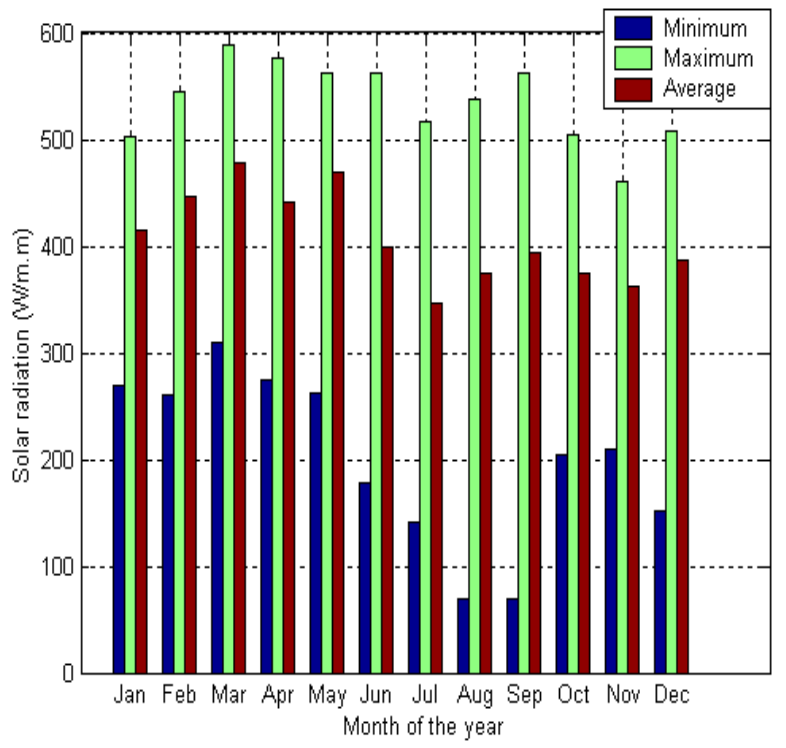

Fig. 5 Minimum, maximum and average monthly solar radiation in $\mathrm{W} / \mathrm{m}^{2}$ for the year of 2015 


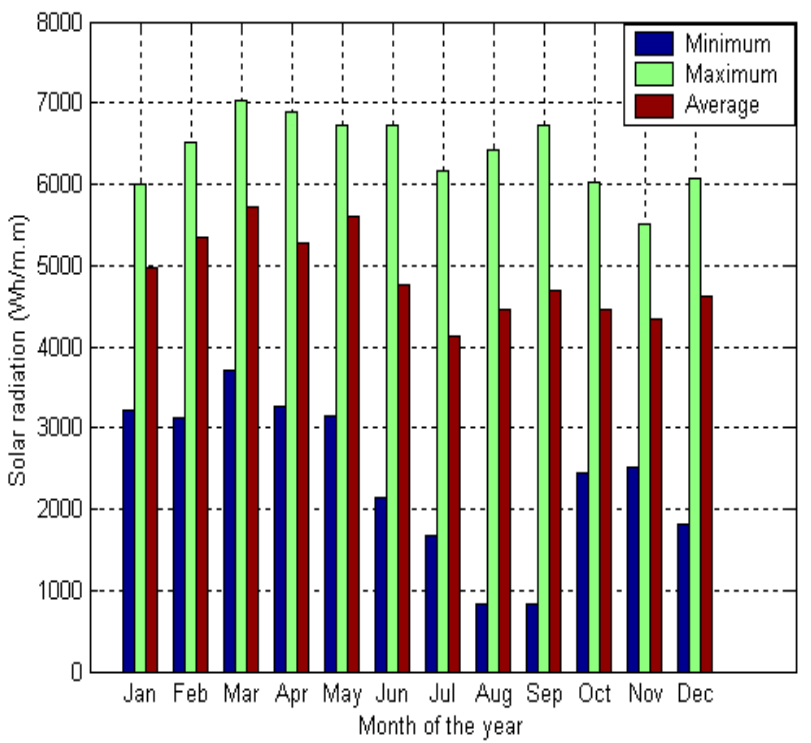

Fig. 6 Minimum, maximum and average monthly solar radiation in $\mathrm{Wh} / \mathrm{m}^{2}$ for the year of 2015

TABLE I

THE LOWEST MINIMUM, HIGHEST MAXIMUM AND LOWEST AVERAGE MONTHLY SOLAR RADIATION FOR THE YEAR OF 2015

\begin{tabular}{|l|c|c|c|}
\hline & $\begin{array}{c}\text { Lowest } \\
\text { minimum }\end{array}$ & Highest & $\begin{array}{c}\text { Lowest } \\
\text { average }\end{array}$ \\
\hline $\begin{array}{l}\text { Solar radiation } \\
\text { in }\left(\mathbf{W} / \mathbf{m}^{2} \text { ) }\right.\end{array}$ & $\begin{array}{c}68.73 \\
\text { (in August and } \\
\text { September) }\end{array}$ & $\begin{array}{c}589.30 \\
\text { (in March) }\end{array}$ & $\begin{array}{c}346.10 \\
\text { (in July) }\end{array}$ \\
\hline $\begin{array}{l}\text { Solar radiation } \\
\text { in }\left(\mathbf{W h} / \mathbf{m}^{\mathbf{2}} \text { ) }\right.\end{array}$ & $\begin{array}{c}820.94 \\
\text { (in August and } \\
\text { September) }\end{array}$ & $\begin{array}{c}7038.86 \\
\text { (in March) }\end{array}$ & $\begin{array}{l}4133.94 \\
\text { (in July) }\end{array}$ \\
\hline
\end{tabular}

Fig. 5, 6 and Table I show that the lowest minimum monthly solar radiation of $68.73 \mathrm{~W} / \mathrm{m}^{2}$ or $820.94 \mathrm{Wh} / \mathrm{m}^{2}$ in August and September 2016 was a solar radiation value that was not suitable for generating the SPWM TPVI system. But the highest solar radiation of $589.30 \mathrm{~W} / \mathrm{m}^{2}$ or $7038.86 \mathrm{Wh} / \mathrm{m}^{2}$ in March 2015 was very good and suitable for generating the SPWM TPVI system. The lowest average monthly solar radiations of $346.10 \mathrm{~W} / \mathrm{m}^{2}$ or $4133.94 \mathrm{Wh} / \mathrm{m}^{2}$ occurred in July 2015 , it is still higher than $250 \mathrm{~W} / \mathrm{m}^{2}$ or $3000 \mathrm{Wh} / \mathrm{m}^{2}$ and indicates that the solar radiation every month of the year has a good solar radiation and suitable for generating the SPWM TPVI system.

The average monthly solar radiation for the year of 2015 is $407.0 \mathrm{~W} / \mathrm{m}^{2}$ or $4861.44 \mathrm{Wh} / \mathrm{m}^{2}$. It is classified in very high solar radiation and indicates that the sky in Kangar is very clear and very suitable for generating the SPWM TPVI system.

\section{B. Optimum Sizing of SPWM TPVI System}

The daily solar irradiance and temperature through the year of 2015 are used to optimize the sizing of SPWM TPVI system. The solar irradiance and temperature affect the performance of PV module and also the performance of SPWM TPVI. If the solar irradiance increase, therefore the power of PV module and the power of SPWM TPVI will also increase. Inversely, if the solar irradiance decrease, therefore the power of PV module and the power of SPWM TPVI will also decrease.

Normally, the power capacity of inverter is based on the capacity of switching component and transformer. But the power capacity of SPWM TPVI depends on the switching component, LC filter and the power of PV module. It is due to the SPWM TPV does not apply a transformer as its function to convert $\mathrm{AC}$ low level voltage to $\mathrm{AC}$ high level voltage and provide a required power. In case of SPWM TPVI system, the $\mathrm{AC}$ voltage is converted directly by the full bridge circuit from the PV module voltage. The PV current is flowed the SPWM TPVI system to supply the AC load when the PV module voltage is converted to be AC voltage. It means that the AC required power of SPWM TPVI system depends on the PV module power availability. And also that PV module power availability depends on the solar irradiance and temperature.

The above explanation can be decided that an optimum sizing of SPWM TPVI system is very important to be studied in term of PV module number. The SPWM TPVI system is designed by using MOSFET IRFP 450 that can flow the current of $14 \mathrm{~A}$, but at the LC filter can only flow the current of $5 \mathrm{~A}$, thus the AC current capacity of SPWM TPVI is $5 \mathrm{~A}$. If the SPWM TPVI AC voltage is $240 \mathrm{~V}$ with unity power factor, therefore it has maximum capability power is $1200 \mathrm{~W}$.

\section{Daily Solar Irradiance, Temperature and Performance of PV Module Through The Year of 2015}

The daily solar irradiance and temperature through the year of 2015 as shown in Fig. 7 and 8 was observed and analyzed to obtain the power of PV module as shown in Fig. 10 The maximum and minimum solar irradiance that related to the temperature for the same day are shown in Table II. It means to show that effect of solar irradiance and temperature on the power of $3 \times 60 \mathrm{~W}, 91.8 \mathrm{~V}$, Kaneka G-SA060 amorphous silicon (a-Si) PV module (the higher solar irradiance produces higher PV module power).

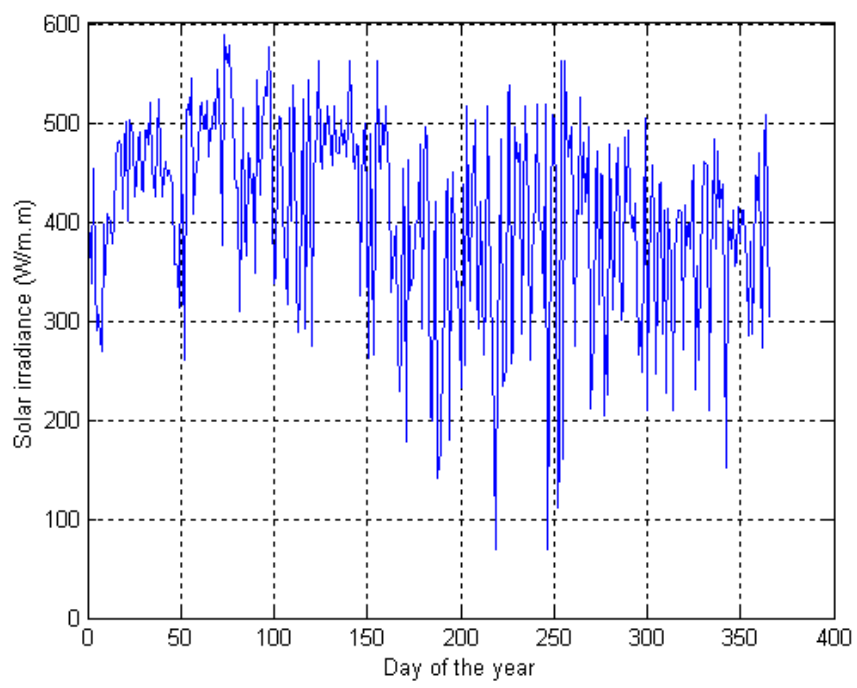

Fig. 7 Daily solar irradiance through the year of 2015 


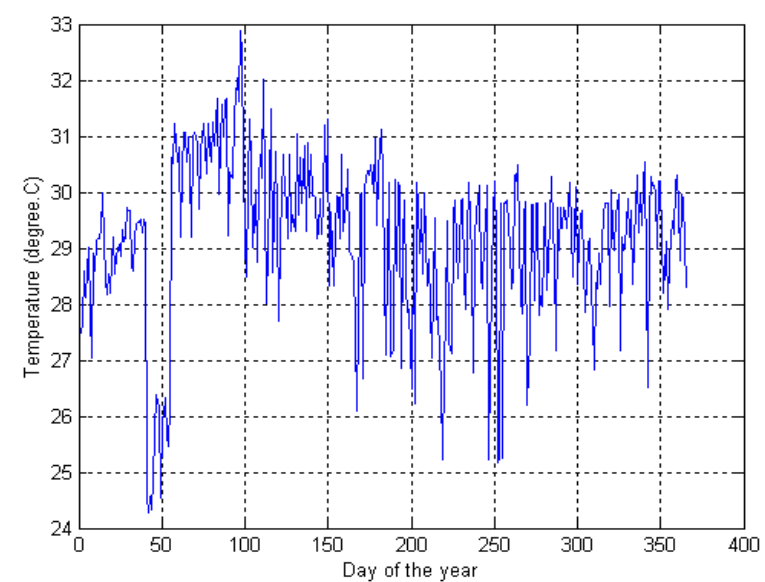

Fig. 8 Daily temperature through the year of 2015

TABLE II

MINIMUM AND MAXIMUM OF THE SOLAR IRRADIANCE AND PV MODULE POWER

\begin{tabular}{|c|c|c|}
\hline & $\begin{array}{c}\text { Solar irradiance } \\
\left(\mathbf{W} / \mathbf{m}^{2}\right)\end{array}$ & $\begin{array}{c}\text { PV module power } \\
(\mathbf{W})\end{array}$ \\
\hline Minimum & $\begin{array}{c}68.73\left(25.23^{\circ} \mathrm{C}\right) \\
\text { on } 7 \text { August } 2015\end{array}$ \\
\hline Maximum & $\begin{array}{c}589.3\left(30.76{ }^{\circ} \mathrm{C}\right) \\
\text { on } 15 \text { March } 2015\end{array}$ \\
\hline Average & $406.77\left(29.18^{\circ} \mathrm{C}\right)$ & 83.99 \\
\hline
\end{tabular}

The daily solar irradiance and temperature is applied into (3) to (5) to obtain the current verses voltage and power verses voltage of $60 \mathrm{~W}, 91.8 \mathrm{~V}$ and $3 \times 60 \mathrm{~W}, 91.8 \mathrm{~V}$, Kaneka GSA060 amorphous silicon (a-Si) PV module as shown in Fig. 9 to Fig. 11. The figures show the generated performance of $3 \mathrm{x}$ 60 W, 91.8 V, Kaneka G-SA060 amorphous silicon (a-Si) PV module in term of current, voltage and power. The daily power of $3 \times 60 \mathrm{~W}, 91.8 \mathrm{~V}$, Kaneka G-SA060 amorphous silicon (a$\mathrm{Si}$ ) PV module is applied to obtain the optimum sizing of SPWM TPVI system.

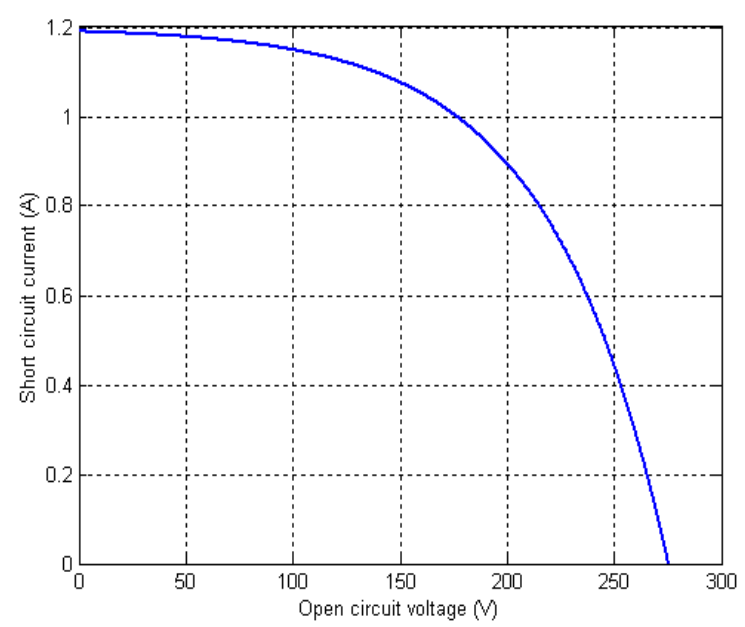

Fig. 9 current verses voltage curve of $3 \times 60 \mathrm{~W}, 91.8 \mathrm{~V}$, Kaneka G-SA060 amorphous silicon (a-Si) PV module

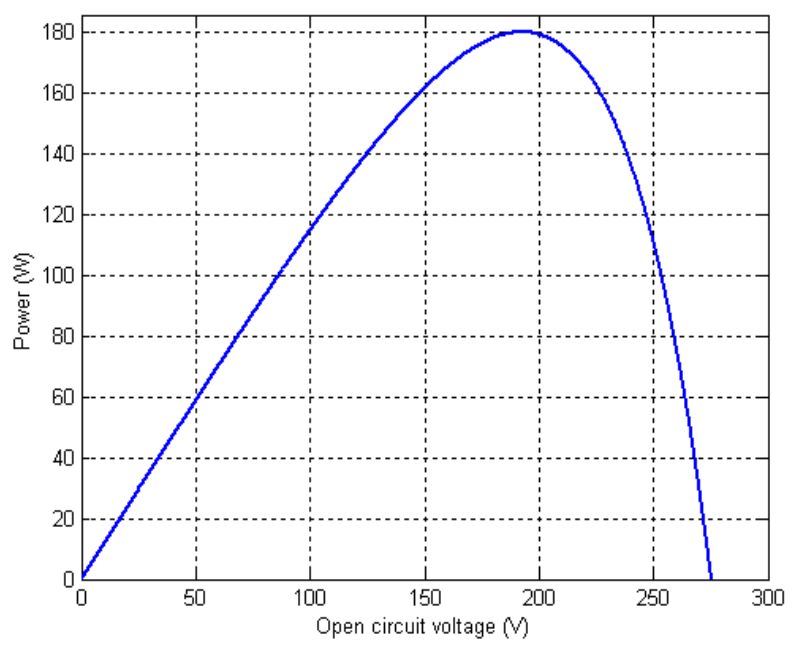

Fig. 10 Power verses voltage curve of $3 \times 60 \mathrm{~W}, 91.8 \mathrm{~V}$, Kaneka G-SA060 amorphous silicon (a-Si) PV module

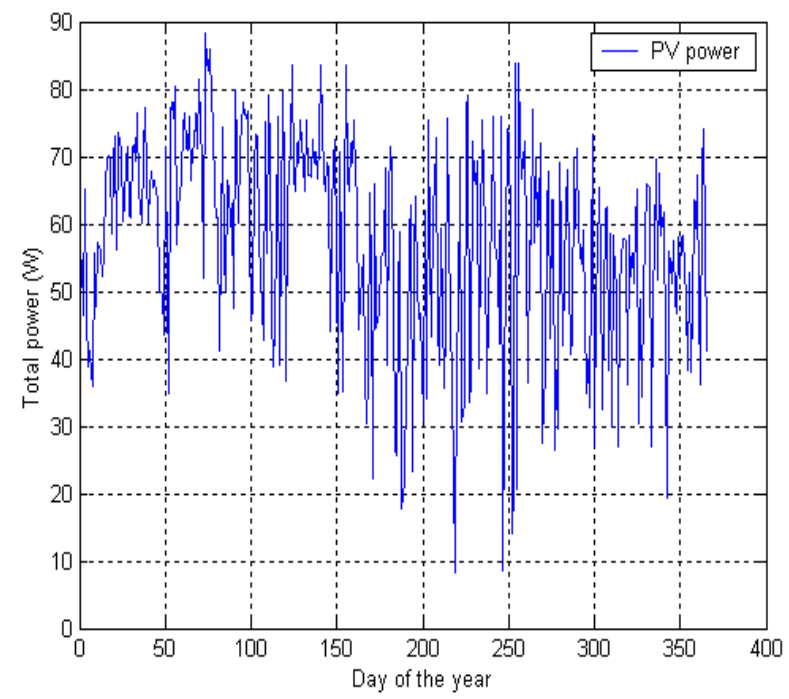

Fig. 11 Daily power of 3 x $60 \mathrm{~W}, 91.8 \mathrm{~V}$, Kaneka G-SA060 amorphous silicon (a-Si) PV module through the year of 2015

\section{Optimum Sizing of PV Module}

Fig. 12 shows the SPWM TPVI demanded power and generated power of $3 \times 60 \mathrm{~W}, 91.8 \mathrm{~V}$, Kaneka G-SA060 amorphous silicon (a-Si) PV module throughout the year of 2015. 


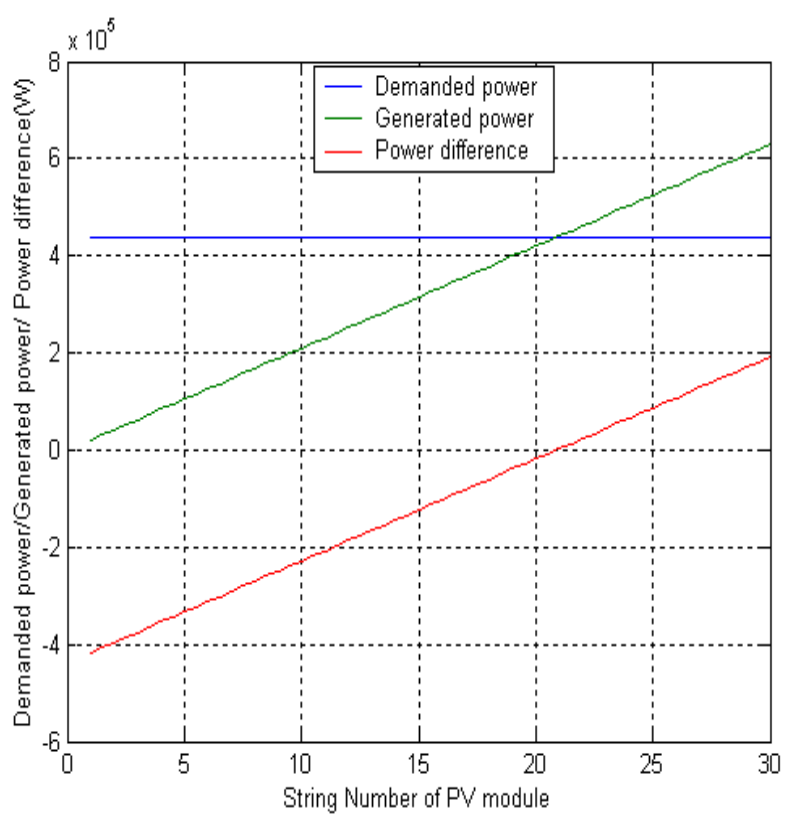

Fig. 12 Demanded power of SPWM TPVI, generated power of 3 x 60 W, 91.8 V, Kaneka G-SA060 amorphous silicon (a-Si) PV module

The optimum sizing of SPWM TPVI system in term of number of PV module is cross section point between curve line of the SPWM TPVI demanded power and generated power of $3 \times 60 \mathrm{~W}, 91.8 \mathrm{~V}$, Kaneka G-SA060 amorphous silicon (a-Si) PV module. Fig. 14 shows the change of PV module number related to demanded and generated power. The optimum PV module string number is 21 (difference between the generated power and demanded power is zero). It is due to there is three PV modules in one string that connected in series, therefore the total number of PV module is 63 to generate the 1200 W SPWM TPVI system.

\section{CONCLUSION}

From the study of optimum sizing modeling of sinusoidal pulse wave modulation (SPWM) transformerless photovoltaic inverter (TPVI) following conclusions can be deduced as follows.

1. Based on solar radiation data through the year 2015 , the average monthly solar radiation for the year of 2015 is $407.0 \mathrm{~W} / \mathrm{m}^{2}$ or $4861.44 \mathrm{Wh} / \mathrm{m}^{2}$. It is classified in very high solar radiation and indicates that the sky in Kangar is very clear and very suitable for generating the SPWM TPVI system.

2. The SPWM TPVI system is designed by using MOSFET IRFP 450 that can flow the current of $14 \mathrm{~A}$, but at the LC filter can only flow the current of $5 \mathrm{~A}$, thus the $\mathrm{AC}$ current capacity of SPWM TPVI is 5 A. If the SPWM TPVI AC voltage is $240 \mathrm{~V}$ with unity power factor, therefore it has maximum capability power is $1200 \mathrm{~W}$. The optimum PV module string number is 21 (difference between the generated power and demanded power is zero). It is due to there is three PV modules in one string that connected in series, therefore the total number of PV module is 63 to generate the $1200 \mathrm{~W}$ SPWM TPVI system.

\section{REFERENCES}

[1] I. Daut, M. Irwanto, M. Ezzani, M. I. Yusoff (2010). Performance of Photovoltaic Module at Different Tilt Angles in Perlis, Northern Malaysia. International Review on Modeling and Simulations (I.RE.MO.S.), Vol. 3, N.6., December 2010.

[2] T. Markvart, Solar Electricity (John Wiley \& Sons, LTD, New York, 1994).

[3] H. Itagaki, M. Okamura, M. Yamada, “ Preparation of Meteorological Data Set Throughout Japan For Suitable Design of PV Systems", $3^{\text {rd }}$ World Conference on Photovoltaic Energy Conversion,, pp. 2074 2077, 2003.

[4] A. Mellit, S.A. Kalogirou, S. Shaari, H. Salhi, A.H. Arab, “ Methodology for Predictiong Sequences of Mean Monthly Clearness Index and Daily Solar radiation Data in Remote Areas: Application for Sizing a Stand-alone PV System", Renewable Energy, Science Direct, pp. $1570-1590,2007$.

[5] I. Dauta, M. Irwantoa, Y.M. Irwana, N. Gomesha, N.S. Ahmad. Three Level Single Phase Photovoltaic and Wind Power Hybrid Inverter. Energy Procedia 18, 1307 - 1316, 2012 https://doi.org/10.1016/j.egypro.2012.05.148.

[6] I. Daut , M. Irwanto, Y.M. Irwan, N. Gomesh, N. S. Ahmad "Optimization of Current Total Harmonic Distortion on Three-Level Transformerless Photovoltaic Inverter", Journal of Energy Procedia 14, 1560-1565, Elsevier, 2012

[7] B. Kavidha, K. Rajambal. Transformerless cascaded inverter topology for photovoltaic applications, Proceeding of Indian International Conference on Power Electronics, 328-331, 2006 https://doi.org/10.1109/iicpe.2006.4685391.

[8] R. Gonzales, L. Lopez, P. Sanchis, E. Gubia, A.Ursua, A., \& L. Marroyo.. High-efficiency transformerless single-phase photovoltaic inverter, IEEE Explore, 2006.

[9] O. Lopes, R. Teodorescu \& J. D. Gandoy. Multilevel transformerless topologies for single-phase grid-connected converter, IEEE Explore, 2006. https://doi.org/10.1109/iecon.2006.347656

[10] W. Kellogg. Optimal unit sizing for hybrid wind/photovoltaic generating system, " Electric Power Systems Research, vol. 39, pp. 3538, 1996 https://doi.org/10.1016/S0378-7796(96)01096-6

[11] B. Ulrick. A Simple Model of Photovoltaic Module Electric Characteristics. IEEE Explore, 2007.

[12] M. Masri, R. Badlishah , M. Irwanto3, H. Alam. Solar Radiation Potential as Energy Source of Photovoltaic Powered Uninterrupted Power Supply in Perlis, Northern Malaysia. IOSR Journal of Electrical and Electronics Engineering (IOSR-JEEE), Volume 9, Issue 6 Ver. II,pp. 31-36, Nov. - Dec. 2014 